\title{
Abuso Sexual InfantoJuvenil: ações municipais da Saúde para a garantia do atendimento
}

\author{
Child sexual abuse: \\ municipal Health Department measures to ensure care
}

Ana Cristina Wanderley da Paixão ${ }^{1}$

Suely Ferreira Deslandes ${ }^{1}$

\footnotetext{
${ }^{1}$ Instituto Fernandes Figueira, Fundação O swaldo Cruz. Av. Rui Barbosa 716, Flamengo. 20250-020 Rio deJaneiro RJ.

acwp@terra.com.br
}

\begin{abstract}
Thearticle analyzes the activities of the M unicipal Department of $\mathrm{H}$ ealth and Civil De fense of Rio de Janeiro in ensuring specialized care for the population of children and adolescents who are the victims of sexual violence. This is a case study that used the method of analysis of content of eight interviews with mid-level managers of the aforesaid $D$ epartment. It was revealed that despite the Department of $\mathrm{H}$ ealth being active in this kind of violence its main intervention is directed to the clinical demands of this kind of injury. With respect to care, it still faces several barriers related to articulation with other institutions, deficiency in the number of services and specialized health professionals, in coverage and in the provision of professional training.

Key words Sexual violence, Child sexual abuse, Public policies
\end{abstract}

Resumo 0 artigo traz uma análise das ações da Secretaria M unicipal de Saúde e D efesa Civil do Rio de Janeiro para garantir o atendimento especializado à população infantojuvenil vítima de violência sexual. Trata-se de um estudo de caso que utilizou o método de análise de conteúdo de oito entrevistas de gestores do nível central desta Secretaria. Verificou-se que apesar da Secretaria ser atuante, sua ação mais evidente está no atendimento às demandas clínicas deste ti po de agravo. No que tange ao atendimento, ela ainda enfrenta vários entraves relacionados a articulações com outras instituições, deficiência no número de serviços e de profissionais de saúde especializados, cobertura e oferta de capacitações.

Palavras-chave Violência sexual, M aus-tratos sexuais infantis, Políticas públicas 


\section{Introdução}

O abuso sexual por sua representação social e repercussões à saúde se destaca como uma das mais impactantes formas de violência contra crianças e adolescentes. O Brasil, comprometido com a Convenção de Direitos H umanos, passou, a partir de $1990^{1}$, a investir na formulação de políticas e medidas visando o enfrentamento destetipo de violência.

Visando afirmar estratégias de ações governamentais e não governamentais, o M inistério da Justiça / Secretaria de Estado dos Direitos Humanos instituiu, em 2000, o Plano N acional de Enfrentamento da Violência Sexual Contra Crianças e Adolescentes. Seu objetivo consistia em assegurar um instrumento legítimo de garantia de direitos e defesa de crianças e adolescentes e fornecer diretrizes para a viabilização da política de atendimento estabelecida pelo Estatuto da Criança e Adolescente. Com vistas à sua realização, ele seria disseminado através de planos estaduais e municipais adaptados para as necessidades e condições de cada local ${ }^{2}$. Atualmente, todos os estados brasilei ros possuem planos de enfrentamento da violência sexual ${ }^{3}$.

O Rio deJaneiro construiu seu Plano Estadual em 2006. Seu quadro operacional é estruturado em torno dos seis eixos estratégicos do Plano $\mathrm{Na}$ cional, quais sejam: a. análise da situação; b. mobilização e articulação; c. defesa e responsabilização; d. atendimento; e. prevenção ef. protagonismo infantojuvenil ${ }^{4}$. Seus objetivos são semelhantes, porém adaptados às possibilidades do Estado. 0 Rio de Janeiro também já tem o seu Plano Municipal de Enfrentamento da Violência Sexual Contra Crianças e Adolescentes (PM EVSCA) pronto desde2009, porém ainda em vias de publicação. Considerando o fato deste Plano ainda não ter sido referendado, o presente artigo analisa as ações realizadas pela Secretaria Municipal deSaúde e Defesa Civil do Rio de Janeiro (SM SDC-RJ) relativas às diretrizes estabelecidas no eixo "atendimento" do Plano Estadual deEnfrentamento da Violência Sexual Contra Crianças e Adolescentes do Rio de Janeiro (PEEVSCA) focando o objetivo "Garantir 0 atendimento especializado às crianças e adolescentes vítimas de violência sexual e a suas famílias, incluindo o abusador".

\section{Metodologia}

Esta pesquisa traz um estudo de caso das ações realizadas no nível central da SMSDC-RJ para garantir atendimento especializado às crianças e adolescentes vítimas de abuso sexual, com extensão a seus familiares e autores da agressão. A escolha deste município como caso deve-se ao seu pioneirismo na instituição da notificação de maus-tratos, à complexidade de sua rede pública de saúde, por possuir um Núcleo de Promoção da Solidariedade e Prevenção das Violências e uma da Comissão Municipal de Enfrentamento das Violências Sexuais contra Crianças eAdolescentes, revelando possuir larga experiência na abordagem do tema.

Segundo Yin ${ }^{5}$, o estudo de caso é uma investigação de base empírica que pesquisa um fenômeno contemporâneo dentro de seu contexto da vida real, especialmente quando os limites entre os fenômenos e o contexto não estão claramente definidos. Possibilita uma descrição aprofundadaeuma análise mais detal hada do caso em questão, com o objetivo de compreendêlo em seus próprios termos.

\section{Operacionalização do Estudo}

As técnicas e instrumentos utilizados foram denatureza qualitativa. Partindo do princípio que existe uma relação dinâmica entre fatos reais e a subjetividade dos atores que os vivenciam, esta abordagem foi escolhida no intuito de compreender as relações, visões e avaliações dos vários atores sobreo processo do qual participam, procurando entender como suas experiências e representações estão vinculadas ${ }^{6}$.

Foram feitas oito entrevistas semiestruturadas com gestores das Gerências de Programa da Mulher, do Adolescente e da Criança, Assessoria de Promoção da Saúde e Superintendência de Atenção Primária do nível central da SM SDC-RJ no período de maio a junho de2010. Oscritérios deinclusão foram: ser gestor do nível central (superintendentes, gerentes de programas atuantes na atenção às crianças e adolescentes) ou ser membro designado pela SM SDC-RJ no ConseIho M unicipal de Direitos da Criança e do Adolescente. D os oito entrevistados, apenas doisocupavam o cargo há cerca de um ano. Os demais já atuavam no nível central da SM SDC-RJ durante a construção do PMEVSCA.

As gravações realizadas em ambiente reservado, respeitando a privacidade dos depoentes. Posteriormente, elas foram integralmente transcritas e identificadas com a letra $G$, numerada de 1 a 8 (G1, G2, G3 etc). N o intuito de preservar o anonimato dos entrevistados, foram todos considerados do sexo masculino. 
As entrevistas identificaram as ações da SM SDC-RJ voltadas para 0 atendimento especializado às crianças e adolescentes em situação de violência sexual, seus familiares e autores desse abuso. 0 roteiro abordou os seguintes temas: 0 fluxo de atendimento estabelecido na rede; articulações inter-setoriais; capacitações de gestorese profissionais de saúde, e procedimentos voltados para as vítimas, seus familiares e autores do abuso. A pós relato livre, foi demandado aos entrevistados que detal hassem o histórico de implementação, objetivos, público-alvo, duração, abrangência, capacidade de articulações inter-setoriais, resultados e avaliações das ações relatadas.

0 acervo foi transcrito e analisado segundo os princípios da análise de conteúdo ${ }^{7}$, a partir de sua modalidade temática adaptada por M inayo. Priorizou-se, portanto, a interpretação hermenêutica dos sentidos latentes e manifestos nos relatos, em detrimento de codificações estatísticas de sua ocorrência.

A análise das entrevistas constou de uma fase de pré-análise onde foi feita uma leitura para estabelecer contacto com a integralidade discursiva do acervo, procurando identificar informações pertinentes aos temas pesquisados. Procedeu-se então à categorização dos temas e subtemas. Buscou-se contextualizar este material com a realidade do atendimento na rede pública municipal eas condições de acompanhamento e suporte às vítimas de abuso sexual, seus familiares e autores da agressão, relatadas na literatura.

Finalmente, foram destacadas as informações pertinentes obtidas einterpretadas de acordo com o quadro teórico proposto ${ }^{9}$, qual seja, os objetivos do eixo atendimento do Plano Estadual. Esta pesquisa foi submetida e aprovada pelo Comitê deÉtica da Secretaria M unicipal de Saúdee D efesa Civil do Rio de Janeiro (SM SDC-RJ).

\section{Resultadosediscussão}

\section{O Entendimento dos Gestores sobre os Planos Estadual e M unicipal}

O PEEVSCA foi construído no âmbito do Fórum deEnfrentamento à Violência Sexual contra Crianças e Adolescentes, composto por entidades da sociedade civil e governamental envolvidas na temática. Sua criação reflete o esforço e o interesse do estado em corresponder à solicitação governamental de implantar e disseminar as políticas de enfrentamento da violência sexual, estabelecidas pelo governo federal. A instituição de um Plano Municipal demonstra a mobilização das organizações municipais para dar continuidade a esta tarefa que, por sua magnitude e complexidade, requer uma conjunção de forças, trabalho deequipee parcerias nem semprefáceis de serem alcançadas.

Foi abordada nas entrevistas a ciência dos gestores sobre o PEEVSCA e a colaboração da SM SDC-RJ na instituição do mesmo. A maioria dos depoentes manifestou conhecimento sobrea existência do Plano Estadual, sem, no entanto, saber o seu teor. Não conheço não. Quer dizer, eu sei que ele existe, mas eu não conheço, não tenho como avaliar o plano (G6). A penas dois gestores referiram uma possível participação da SM SDCRJ na sua elaboração. Provavelmente sim, mas eu já não sei se são as mesmas pessoas. A té estou em dúvida se eu mesmo participei... (G1).

Apesar de se presumir a participação da SM SDC-RJ na construção do Plano Estadual, as entrevistas apontam para uma articulação ainda frágil entre o Estado e o M unicípio na formulação das políticas de enfrentamento da violência sexual. Além disso, refletem uma lacuna na interlocução entre os próprios pares da Secretaria M unicipal e pouca divulgação do Plano Estadual entre gestores municipais que atuam no mesmo campo.

Já no que tange o Plano M unicipal, de forma positiva e engajada na temática, sete entrevistados afirmaram o envolvimento da Saúde na criação do mesmo. Um deles manifestou, inclusive, seu entusiasmo pela retomada dos trabalhos da Comissão M unicipal deEnfrentamento após uma queda progressiva de produção entre2001 e2004.

Essa comissão...criada em 2001...os profissionais se inseriram, ela perdeu um pouco, ela foi diminuindo. Em 2005 tem uma nova chamada e de 2005 pra cá é que eu venho participando (...) com esse objetivo, de formular o Plano M unicipal de Enfrentamento da Violência. (...) Só que não está assim... nós estamos fazendo revisão de (...) mas ele está basicamente pronto.(G5).

Não obstante, parte das entrevistas é pontuada por críticas aos sistemas de gestão da SM SDC-RJ e do próprio Plano, relacionadas à não participação de todos os gerentes de programas na sua criação, à informali dade na divulgação do Plano aos gestores da Secretaria, dificuldadeno processo desensibilização de outras instituições para a temática e eventuais lacunas em sua construção na área da saúde.

A gente soube desse plano num seminário de lançamento que convidaram pra falar. Convidaram o Programa da XXX (...) em função dela ter 
frequentado o Conselho de Direitos... Mas eu, do Programa da YYY não(G8).

O bserva-se aí a denúncia de um viés personalista, dado que os espaços de articulação não são ocupados visando o planejamento das ações institucionais.

\section{A Organização da Rede de Serviços Governamentais}

Para garantir 0 atendimento às vítimas, constam do Plano Estadual ações voltadas para a implantação de serviços especializados em áreas sem cobertura, potencialização de serviçosjá existentes etratamento e acompanhamento das vítimas. Além disso, inclui-se nas diretrizes a promoção de interven ção interdisciplinar qualificada para as vítimas, familiares e agressores, através de rede articulada com instâncias de defesa e criação sistemática de cursos para profissionais que atuem em programas e instituições de atendimento às vítimas4.

Os depoimentos dos gestores sobre a rede de serviços foram diversificados e eventualmente divergentes. Enquanto um deles afirmava a existência de uma rede bem estruturada, dois ignoravam o estabelecimento de qualquer ação da SM SDC-RJ direcionada especificamente para violência sexual de crianças eadolescentes. Outros detalhavam ações como a criação da ficha de notificação, que não era específica, porém englobava a temática. A implantação da ficha de notificação foi a primeira questão que foi colocada. (...) e dentro da ficha de notificação tem a questão da violência sexual (G4).

\section{Fluxo de atendimento}

Dentro da organização da rede, a criação de um fluxo de atendimento foi uma das ações citadas pela maioria dos entrevistados e por eles considerada como fundamental. Segundo relatos, ficaram estabelecidas como porta deentrada para ambos os sexos as emergências e maternidades do M unicípio. Como unidades dereferência para o acompanhamento das crianças e adolescentes do sexo feminino foram eleitos o H ospital Jesus e o Hospital M aternidade Fernando M agalhães respectivamente, eos Centros Municipais deSaúde para os meninos. Entretanto, um entrevistado disse desconhecer para onde encaminhar as adolescentes agredidas para acompanhamento, evidenciando que algumas deliberações dentro do nível central da Secretaria não são partilhadas por todos os membros deste grupo gestor. Este mesmo depoente também afirmou existir certo desconhecimento por parte dos profissionais de saúde e dos Consel hos Tutelares (CT) sobre esta organização de atendimento.

... muitos funcionários de saúde estão encaminhando os casos para o IM L, porque é uma orientação dos Consel hos Tutelares... os profi ssionais de saúde, muitos, não estão com a informação que 0 Jesus é referência... tem que ficar muito claro para os profissionais que identificam o caso, a suspeita ou confirmação, para onde encaminhar, qual 0 papel... e isso não está claro na rede (G4).

Esta fala sinaliza para uma lacuna na interlocução entre o nível central da Secretaria e suas unidades. Observa-se, porém, que essa "falta de conexão" não é primazia do município do Rio de Janeiro ou mesmo do Brasil. M esmo nos Estados Unidos, onde os investimentos na preven ção e tratamento das crianças sexual mente vitimizadas datam da década de 1970, ainda persistem problemas decomunicação entreinstituições. Um estudo, realizado por Alvarez et al. ${ }^{10}$, sobre as falhas dos profissionais em notificarem casos de maus-tratos mostrou que uma das causas poderia ser atribuída à fal ta de clareza das orientações dos Serviços de Proteção às Crianças.

Interrupção legal da gestação

Apesar de não contemplado no escopo do fluxo de atendimento oficial, outro tema extremamente polêmico abordado por dois entrevistados foi a interrupção da gravidez decorrentede violência sexual.

Segundo um entrevistado, a SM SDC-RJ teve como iniciativa a criação do primeiro serviço de aborto legal no SUS para mulheres, extensivo a adolescentes. Ela estabeleceu uma parceria com a UnidadeI ntegrada de Saúde Herculano Pinheiro (UISH P) e com o H ospital M aternidade Fernando Magalhães (HM FM) - este último já atendendo casos de abuso sexual - para que estes fizessem a interrupção das gestações oriundas de violência sexual. Esta junção de iniciativas deu origem a um seminário com um desenho bastantecriativo, promovido pela SM SDC-RJ, onde os profissionais de ambas as unidades, pertencentes à mesma categoria, se reuniram aos pares para trocar experiências e discutir casos já atendidos. Um seminário enriquecedor, já que possibilita novos conhecimentos esugestões para atendimentos com características semelhantes. $\mathrm{Na}$ prática, atualmente, apenas o H M FM segueprestando esse serviço às adolescentes e mulheres.

Contudo, é inquietante pensar que uma me trópole como o Rio de Janeiro, com uma população municipal superior a 6.000 .000 dehabitan- 
tes, só possua um hospital municipal de referência para este tipo de agravo. Outro questionamento quesecoloca éaté que ponto o posicionamento pessoal de alguns gestores frente à "interrupção da gestação" pode influenciar no grau de investimento da implementação desta ação.

No Brasil, a autorização para o aborto nos casos de gravidez resultante de abuso sexual data de 1940, citada no artigo 128 do Código Penal. Em 1998 é publicada pelo M inistério da Saúde uma NormaTécnica sobrePrevenção eTratamento dos Agravos Resultantes da Violência Sexual Contra Crianças eA dolescentes - revisada eampliada em 2005 - que regulamenta 0 aborto legal por meio do SU ${ }^{11}$, dando cumprimento à resolução $n^{\circ} 258$ do Conselho Nacional de Saúde ${ }^{12}$.

Essa ação não él legalizada em todos os países e, em al guns, só épermitida até determinado tempo de gestação. Na Colômbia, por exemplo, o aborto era considerado ilegal em qualquer circunstância até 2006, quando o governo autorizou o primeiro abortamento para uma menina de 11 anos violentada por seu padrasto. Em El Salvador, Chile e Nicarágua esse procedimento continua sendo proibido até hoje. Já na Alemanha, apesar de uma lei de 1995 proibir qualquer indicação de abortamento, em casos de violência sexual, médicos e pacientes não são processados se realizarem a interrupção nas primeiras doze semanas de gestação. Entretanto, o governo não cobre as despesas do procedimento. $\mathrm{Na}$ Rússia, o abortamento nesses casos é permitido até as 22 semanas ${ }^{13}$. A postura de alguns países frente esse problema ainda éum entrave na luta pelos direitos reprodutivos da mulher e da adolescente, submetendo-as ao sofrimento de uma gravidez indesejada, abortamentos ilegais e possíveis complicações que podem comprometer seu futuro reprodutivo ou levá-las à morte ${ }^{14}$.

\section{Articulações inter-setoriais}

Devido à complexidade das demandas do atendimento dos casos de violência sexual, o PEEVSCA prevê a necessidade de articulações constantes entre os setores comprometidos com os desdobramentos da temática em questão. Segundo a maioria dos relatos as articulações intersetoriais eram frequentes, variando a instituição de acordo com o inter esse comum do momento, fosse ele relacionado à implantação das fichas de notificação, fluxo ou produção de capacitações para profissionais. Entre os mencionados, órgãos governamentais como a Secretaria de Estado de Saúde e Defesa Civil do Rio de Janeiro, Justiça, Instituto M édico-Legal, Polícia, Secreta- ria de Assistência Social, Conselho Estadual dos Direitos da Mulher e Ongs como a Cidadania Estudo Pesquisa e Ação, a Universidade Federal do Rio de Janeiro, o Instituto de Pesquisas Sistê micas e Desenvolvimento de Redes Sociais, 0 Núcleo deAtenção à Violência (NAV) a SociedadeBrasileira de Pediatria e o Centro Latino-Americano deEstudos deViolência eSaúdeJorgeCareli eram por el es considerados os parceiros mais constantes. Todavia, dois entrevistados referiram que nos últimos anos houve um decréscimo no estabelecimento de ações voltadas para a violência sexual eque só agora a SM SD C-RJ vem procurando retomar seus trabalhos.

É extremamente positivo comprovar o investimento da SM SDC-RJ para se articular com entidades governamentais e não governamentais no enfrentamento do abuso sexual infantojuvenil. O utras redes deatenção às situações de violências do país também reconhecem que a atuação interinstitucional, mais que um princípio, é de absoluta necessidade perante a complexidade do problema ${ }^{15}$. Contudo, promover articulações e parceriaséum processo quedependedeuma sériede fatores ligados a cada instituição e vislumbra-se a preocupação dos gestores com a descontinuidade dessas ações para a manuten ção da estrutura adequada para esse atendimento. Segundo M oyses et al. ${ }^{16}$, alguns dos obstáculos para se estabelecer a intersetorialidade seriam: a relutância dos segmentos que detém o poder em romper as tradicionais relações de trabalho; a dificuldade dos profissionais de saúde em ampliar seu olhar, muitas vezes contaminado pelo corporativismo, e a dificuldade de compartilhamento do poder face o predomínio da setorização das rubricas do orçamento público, prejudicando a agilidade e a resolutividade das ações.

0 atendimento às famílias

Perante a indagação sobre as ações voltadas para os familiares, pôde-se observar nas entrelinhas dos relatos dos gestores uma atitude favorável nesse sentido, sem, no entanto, sua concretização na rede de serviços. Um entrevistado referiu que dentro do protocolo da SM SDC-RJ é oferecido um atendimento em saúde mental e um encaminhamento ao Serviço Social. No entanto, 0 documento mencionado dita apenas as condutas básicas deatendimento de emergência, locais de atendimento e seguimento e envio da ficha ao CT eSM SDC-RJ, não fazendo dele parte os outros encaminhamentos para a vítima ou seus familiares. Todos os outros depoentes negaram qualquer procedimento por parte da Secre- 
taria que envolvesse os cuidados supracitados. É mencionada, inclusive, a dificuldade dos gestores para sensibilizar a área de saúde mental da importância deste tipo de atendimento:

O rientação da Secretaria, por exemplo, na época a gente não teve muita participação da saúde mental. Foi uma dificuldade nossa. Porque assim, eles estavam muito ocupados com a questão dos transtornos invasivos e ... não conseguiram participar junto com a gente nessa construção, não é?...eu acho que éuma coisa quenão foi solidificada nessa área, sabe? (G8).

Esta fala desenha claramente a intenção dos gestores municipais em aprimorar 0 atendimento às famílias e os entraves que enfrentam para a concretização de um bom atendimento.

Outro relato, num entendimento peculiar sobre o papel da SMSDC-RJ na promoção de atenção às famílias, debita tal responsabilidade à atuação do CT e às unidades de saúde diante do atendimento, não incluindo a própria secretaria na construção desta dinâmica de trabalho.

(...) vocêtem que fazer... é notificar ao ConseIho Tutelar. 0 próprio Conselho Tutelar, quando as famílias não vão, eles vão lá chamar... ter contacto com a família..., porque 0 atendimento da criança e do adolescente tem queter a parti cipação da família... faz parte da N orma Técnica, mas aí é feito mais nas unidades onde está acontecendo 0 atendimento, não é? (...) não tem uma norma da Secretaria, uma ação determinada, voltada para isso (G7).

Dois entrevistados citaram como ação voltada para os familiares das vítimas apenas a produção de uma cartilha "Protegendo nossas crianças e adolescentes". Essa publicação, voltada para a prevenção é dirigida para a conduta dos pais perante os vários ti pos de violência que podem cometer contra suas crianças e adolescentes, mas não constitui um procedimento direcionado especificamente para os familiares das vítimas de abuso.

Em 2005, no município do Rio de Janeiro, de 269 casos de abuso sexual atendidos, 191 foram de origem intrafamiliar, sendo $47 \%$ deles perpetrados por pais ou padrastos ${ }^{17}$. M ediante as circunstâncias em que sucedeu a violência sexual e por quem foi cometida, as reações familiares podem percorrer trajetos, desde a preocupação com a vítima pelo trauma sofrido até a vergonha, descrédito e desestruturação familiar ${ }^{18}$. Independente da forma como ocorreu a agressão, os parentes próximos da criança ou do adolescentenecessitam de suporte, seja elemental, social ou mesmo econômico. Corroborando com este preceito, Carvalho et al. ${ }^{19}$ num estudo da percepção materna sobre o abuso sexual de suas filhas, constataram ser enfática a dificuldade das mães em conviver com a sensação de culpa por não terem podido evitar o sofrimento de suas filhas. Leventhal et al. ${ }^{20}$ acreditam que, apesar das intensas reações dos pais ao abuso, estes se encontram despreparados para lidar com as sequelas emocionais e sociocomportamentais dos filhos vitimizados. Além disso, a sociedade tende a culpabilizar a família pelo abuso e pelo estado em que a criança se encontra, chegando até a minimizar a atuação do agressor. Os autores afiançam ser necessário estender o tratamento à família, ajudando-Ihes a seorganizar após a agressão vivida. Yancey eH ansen ${ }^{21}$ consideram estetipo desuportepsicológico um importantefator prognóstico para a resiliência da criança. Entretanto, Ferreira ${ }^{22}$, numa avaliação de um ambulatório da família, ressaltou que havia muita resistência dasfamílias ao comparecimento à psi col ogia, muitas vezes não chegando sequer a agendar a primeira consulta. A autora atribuiu o fato às características do atendimento psicológico eao preconceito e estigma que podem envolver esse tipo de tratamento. Sustentando esta posição, Araújo ${ }^{23}$ afirma que, apesar do atendimento às famílias ser fundamental, a carga de ansiedadeétão grande que elas tentam fugir dele, sendo por vezes necessário apoio legal para mantêlas em acompanhamento.

0 atendimento ao autor do abuso

Foi citado por dois entrevistados um projeto de atendimento em parceria com o NAV para o atendimento aos autores das agressões, mas atualmente extinto por falta de verba municipal. Sustentando a consideração da Secretaria sobre a temática, um deles ainda acrescentou que, apesar deterem sofrido pressão por parte do M inistério Público e do Juizado para que o autor da agressão recebesse tratamento, após conversa com seus pares os gestores concluíram que não dispunham de pessoal suficiente para este tipo de atendimento, já que para tal necessitariam supostamente de duas equipes, uma para atender à vítima e outra para 0 autor da violência.

Os outros depoentes foram taxativos em negar qualquer procedimento neste sentido. Um deles, apesar de reconhecer o mérito desse atendimento, isentou a Saúde desta responsabilidade. É super importanteter alguém quefaça 0 atendimento do agressor mas não é o papel da Secretaria M unicipal de Saúde, ou pelo menos nós não enxergamos nesse momento (G6). 
Contrapondo-se ao estigma e à exclusão do autor da violência sexual, o atendimento ao agressor é hoje uma reivindicação das entidades que trabalham com a temática. Esteacompanhamento faz parte da política nacional de enfrentamento à violência sexual contra crianças e adolescentes, encontrando-se definido não só no PEEVSCA-RJ como no Plano Nacional.

Segundo estudos ${ }^{24}$, no Brasil são muito poucos os serviços de atendimento a homens autores de agressão. No Rio de janeiro, os atendimentos são realizados por duas instituições não governamentais, NAV eNOOS (Instituto de Pesquisas Sistêmicas e Desenvolvimento de Redes Sociais).

0 atendimento aos agressores sexuais já é uma realidade em outros países. Na América Latina, o M éxico foi o pioneiro em criar programas de atendimento a homens acusados de violência. Atualmentejáse encontra consolidado este tipo de atenção na Argentina, Peru, Nicarágua, H onduras e Chile, sendo que estes dois últimos oferecem programas governamentai $s^{24}$. Nos Estados Unidos, em 1996, o National Institute of Corrections e o State Justice Institute criaram o Center for Sex Offender M anagement (CSOM) visando oferecer suporte, intercâmbio de informações, trei namento eassi stência técnica a jurisdições locais e estaduais no atendimento a autores de violência sexual. Atualmente, todos os estados americanos possuem serviços de atendimento ao agressor e seus profissionais e membros das comunidades podem se capacitar com o CSOM ${ }^{25}$. Na N ova Zelândia, o Department of Corrections oferece programas de tratamento para agressores sexuais não só enquanto prisioneiros como também após serem soltos. Eles, inclusive, classificam o agressor segundo seu risco dereincidência edirecionam o tratamento mais adequado para a sua idade e para o tipo de vítima escolhida (adultos, adolescentes, crianças) ${ }^{26}$.

\section{Capacitações}

Ainda no propósito da organização da rede de atendimento, as capacitações foram outro objeto de questionamento. N ovamente os relatos não foram convergentes. Dois entrevistados ignoravam ter havido qualquer tipo de capacitação, fosse ao nível de gestão ou de outros profissionais. Quanto à habilitação dos próprios gestores, a maioria referiu só ter ocorrido na fase da implantação do fluxo deatendimento. Deforma mais ampliada, um entrevistado colocou em pauta a postura favorável da SM SDC-RJ frente às ca- pacitações de seus profissionais. Prá nós do nível central não. 0 que a Secretaria nos oferece como oferece a qualquer profissional éa possibilidade de liberação de uma carga horária... um abono de ponto... (G6).

Subentende-se nesta fala que, apesar de os gestores ainda se encontrarem deficitários em capacitações, existe 0 interesse institucional em incentivar 0 aperfeiçoamento de todos os seus membros. Tal abertura contribuiria de forma conclusiva para a formação de agentes multiplicadores de conhecimento nas unidades municipais de ponta.

Vale notar que não foram mencionadas as capacitações que abordavam a temática da violência, realizadas em 2008 edirigida às equipes da Estratégia Saúde da Família, envolvendo a participação de 157 profissionais.

Quanto aos profissionais de saúde, a maior parte dos entrevistados afirmou ter havido capacitações para os mesmos na fase de implantação da nova ficha de notificação/investigação individual de violência doméstica, sexual e/ou outras violências, negando, porém, que fossem permanentes, conforme as diretrizes do PEEVSCA apregoam. Reconhecendo as limitações de ofertas de aperfeiçoamento proporcionadas pela SM SD C-RJ, refere um gestor:

A gente ofereceu aquela capacitação. N ão houve uma educação permanente em relação às ações que a gente... a gente se ressente disso, a gente não conseguiu acompanhar aquelas equipes capacitando de uma forma sistemática... o quea gente tem é assim, algumas ações pontuais de fazer um seminário, ou dentro de um centro de estudos de promoção de saúde, fazer alguma questão em relação à violência. (G8).

A partir deste relato deduz-se que os profissionais de saúde diretamente envolvidos, apesar de terem recebido uma primeira orientação e participado de eventuais grupos de estudo, precisam ainda ser beneficiados com um suporte educacional mais sistemático. Tal medida minimizaria o eventual risco de expor as vítimas de abuso sexual a condutas clinicamente não padronizadas e a encaminhamentos inadequados.

Já outro entrevistado afirmou que o programa da mulher, com a participação dos programas da criança edo adolescente faz, anualmente, capacitações teóricas e discussão de casos, oferecendo vagas às unidades municipais. Estas seriam voltadas para as equipes que atendem violência sexual, com perfil multiprofissional. 
O acompanhamento e avaliação

das ações realizadas

Ao serem questionados sobre ter havido algum monitoramento ou avaliação das ações voltadas para a violência sexual infantojuvenil, os entrevistados negaram qualquer tipo de iniciativa dentro da SM SDC-RJ.

O acompanhamento contínuo do desenvolvimento de programas e políticas é uma função inerente ao processo de gestão que, através de indicadores estabelecidos com base em fontes de dados diversas, fornece aos gerentes informações de desempenho que permitem medir se 0 propósito e 0 alvo estão sendo alcançados ${ }^{27}$.

A grande maioria dos gestores desconhece qualquer tipo de avaliação oficial das ações da SM SD C-RJ relacionadas ao enfrentamento da violência sexual infantojuvenil. Um entrevistado referiu uma avaliação interna voltada para o acompanhamento eo índice de abandono decrianças no Hospital J esus nos primeiros dois anos de parceria, feita através de fichas de atendimento. Outro gestor mencionou a existência de uma avaliação feita pela Escola de Serviço Social da Universidade Federal do Rio de Janeiro.

A avaliação proporciona não só uma análise dos investimentos realizados para a concretização da política proposta pelo governo no que tange a qualidade, quantidade das ações e gastos públicos como também descortina as razões dos êxitos e fracassos, considerando a situação contextual que favoreça ou dificulteo seu andamento (dispositivos legais, vontade política, disponibilidade financeira, condições sociais e valores culturais ou religiosos) $)^{22}$. Ela abreum campo para sugestões e correções e também reflete a transparência dos atos concretizados.

Não foi mencionado pelos entrevistados que em junho de 2007 o Tribunal de Contas municipal fez uma avaliação sobre o Programa da MuIher onde a violência sexual contra a mulher e a adolescenteé rapidamente abordada, no que diz respeito a locais e tipos de atendimento, treinamento profissional einsumos, sem maiores aprofundamentos sobre 0 assunto ${ }^{28}$. Ratificando um depoimento, verificou-seque o Núcleo de Saúde Reprodutiva e Trabalho Feminino da Escola de Serviço Social da UFRJ, em 2004, também realizou uma avaliação sobre a prevenção da violência sexual no nível de atenção primária no Programa de Assistência Integral à Saúde da M ulher (PAISM) ${ }^{29}$.

\section{Conclusões}

Importantes investimentos têm sido realizados pela SM SDC-RJ para combater a violência sexual infantojuvenil no quetange a parcerias, articulações e grupos de trabalho. Todavia ainda existem muitos percalços que limitam seus resultados. Sob o ponto de vista mais ampliado, observa-se que prevalece entre os gestores pouco conhecimento sobre os documentos instituídos para a temática, com consequente baixa repercussão da política de enfrentamento. Seu entendimento sobre a "garantia de atendimento especializado" mostra-se restrito às vítimas, sendo os familiares e os autores da violência pouco considerados. Apesar de ter um fluxo operante, sua capacidade de cobertura é ainda baixa e pouco divulgada, sem perspectivas de ampliação de número de serviços preparados para atuar. Além disso, com um investimento assistemático nas capacitações, conta com número insuficiente de profissionais especializados em violência sexual infantojuvenil.

0 estudo permite ainda perceber queexistem várias iniciativas e sugestões individualizadas de implementação do atendimento especializado, porém muitas das propostas de ações não seconcretizam ou não têm continuidade. Aponta-se para uma articulação e comunicação precárias não só entre os próprios gerentes como com outras instituições.

Todavia, estes problemas de atuação do setor municipal de uma grandemetrópolecomo o Rio são semel hantes a diversas outras capitais brasileiras. Estudo desenvolvido em cinco capitais do país ${ }^{30}$ apontam problemas semelhantes para 0 atendimento às vítimas de violências: obstáculos para a articulação intersetorial e mesmo dificuldade de estabelecer fluxos intra-setoriais para 0 atendimento, desconhecimento dos gestores de saúde acerca das políticas setoriais de enfrentamento da violência, falta de atendimento para o auto da agressão e descontinuidade das capacitações.

Avaliações sobre serviços de atendimento a crianças eadolescentes vítimas de violência eseus familiares realizadas no âmbito da Saúde ${ }^{31,32}$ evidencia consideráveis lacunas: nem todos possuem equipes multidisciplinares; tampouco suas equipes destinam sua carga horária integralmente ao serviço; predomina o enfoque na díade criança-mãe agressora, pouco abordando sistemicamente a família em suas dinâmicas. Também se constatam problemas de articulação intrassetorial para garantir atendimento psicoterápico de 
mais longa duração e os de dependência a substâncias. Verificam-se ainda problemas de comunicação e circulação da informação entre serviços de saúde e Consel hos Tutelares.

Conclui-se, portanto, que a SM SDC-RJ tem muitos desafios a superar, mas não tão distintos daqueles encontrados no setor Saúde país afora. Outrossim, precisa investir na interlocução de suas gerências, na articulação entre unidades e nível central, nos processos de capacitação, na preservação da memória eavaliação de suas ações a fim de garantir o atendimento de qualidade às vítimas desse tipo de violência.

\section{Colaboradores}

As autoras ACW Paixão e SF Deslandes participaram equitativamente da elaboração de todo 0 texto.

\section{Referências}

1. Doek JE. The CRC 20 years: an overview of some of major achievements and remaining challenges. Child Abuse \& Neglect 2009; 33(11):771-782.

2. Brasil. M inistério da Justiça. Plano Nacional de Enfrentamento da Violência Sexual Infanto-Juvenil. $3^{\circ}$ ed. Brasília: SEDH, DCA; 2002.

3. Agência de notícias dos direitos da infância (ANDI). Informações sobre os Planos Estaduais. [periódico na Internet] 2009 maio15 [acessado 2010 jul 7]. Disponível em: htpp://www.andi.org/pdfs/informacao_ sobre_os_planos_estaduais.pdf

4. Conselho Estadual de Defesa da Criança e do Adolescente do Rio de Janeiro. Plano de Enfrentamento à violência sexual contra crianças e adolescentes do Estado do Rio de Janeiro. Rio de Janeiro: Artes Gráficas Edil; 2004.

5. Yin R. Estudo de caso: planejamento e métodos. Porto Alegre: Bookman; 2005.

6. M inayo M CS, Souza ER, Constantino P, Santos NC. $M$ étodos, técnicas e relações em triangulação. In: In: M inayo MCS, Assis SG, Souza ER, organizadoras. Avaliação por triangulação de métodos: abordagem de programas sociais. Rio de Janeiro: Editoria Fiocruz; p. 71-104.

7. Bardin L. Análise de Conteúdo. Lisboa: Edições 70; 1979.

8. M inayo M CS. O Conceito de representações sociais dentro da sociologia clássica. In: Guareschi PA, Jovchelovitch $\mathrm{S}$, organizadores. Textos em representações sociais. Rio de Janeiro: Vozes; 2002. p. 89-111.

9. M inayo M CS. 0 desafio do conhecimento: pesquisa qualitativa em saúde. 7a ed. São Paulo: Hucitec; Rio de Janeiro: Abrasco; 2000.

10. Alvarez KM, Kenny M C, Donohue B, Carpin KM . Why are professionals failing to initiate mandated reports of child maltreatment, and are there any empirically based training programs to assist professionals in the reporting process. Aggression and Violent Behavior 2004; 9(5):563-578. 
11. Brasil. M inistério da Saúde. Norma Técnica - prevenção e tratamento dos agravos resultantes da violência sexual contra mulheres e adolescentes. 2a ed. Brasília: M inistério da Saúde; 2005.

12. Brasil. M inistério da Saúde. Resolução 258. 1997 [acessado 2010 mar 30]. Disponível em: http:// conselho.saude.gov.br/resolucoes/reso_97.htm

13. The Pew Forum on religion and public life. Abortion laws around the world. [periódico na Internet] 2008 set 30 [acessado 2010 mar 26]; Disponível em http://pewforum.org/Abortion/Abortion-LawsAround-the-World.aspx

14. Sexual Violence. IPAS. [acessado 2010 jul 16]. Disponível em: http://www.ipas.org/Topics?Sexual_ Violence.aspx.

15. Brasília. Secretaria de Estado de Saúde do Distrito Federal, Vilela LF, coordenador. M anual para atendimento às vítimas de violência na Rede de Saúde Pública do Distrito Federal. 2oed. Brasília: Secretaria de Estado de Saúde do Distrito Federal; 2009.

16. Moyses SJ, Moyses ST, Krempel MC. Avaliando o processo de construção de políticas públicas de promoção de saúde: a experiência de Curitiba. Cien Saude Colet 2004; 9(3):627-641.

17. Observatório da Infância. Abuso e exploração sexual de crianças e adolescentes no município do Rio de Janeiro: 2002, 2003, 2004, 2005. Dados 2010 [acessado 2010 set 15]. Disponível em: http:// www.observatoriodainfancia.com.br/lM G/pdf/doc98.pdf

18. Habizang LF, Koller S, Azevedo GA, M achado PX. Abuso sexual infantil e dinâmica familiar: aspectos observados em processos jurídicos. Psicologia: Teoria e Pesquisa 2005; 21(3):341-348.

19. Carvalho QCM, Galvão MTG, Cardoso MVML. Abuso sexual infantil: percepção de mães em face do abuso sexual de suas filhas. Rev Latino-Americana de Enfermagem 2009; 17(4):501-506.

20. Leventhal JM, M urphy JL, Asnes AG. Evaluation of child sexual abuse: recognition of overt and latent family concerns. Child A buse $\&$ N eglect 2010; 34:289295.

21. Yancey T, Hansen D. Relationship of personal, familial, and abuse-specific factors with outcome following childhood sexual abuse. Aggression and $\mathrm{Vi-}$ olent Behavior 2010; 15(6):410-421.

22. Ferreira AL. 0 atendimento a crianças vítimas de abuso sexual: avaliação de um serviço público [tese]. Rio de Janeiro: Escola Nacional de Saúde Pública da Fundação Oswaldo Cruz; 2002.
23. Araújo MF. Violência e abuso sexual na família. Psicologia em Estudo 2002; 7(2):3-11.

24. Toneli MJF. Violência Sexual e Saúde M ental: análise dos programas de atendimento a homens autores de violência sexual [Relatório Final de Pesquisa]. Florianópolis: Universidade Federal de Santa Catarina; 2007.

25. Center for Sex Offender M anagement. About Csom. USA 2008 [acessado 2008 maio 23]. Disponível em: http://www.csom.org/about/about.html

26. Department of Corrections of $\mathrm{New}$ Zeland. Programmes for offenders [acessado 2010 maio 30]. Disponível em: htpp://www.corrections.govt.nz/aboutus/fact-sheets/managing-offenders-in-thecommu...

27. Vaitsman J, Rodrigues RWS, Paes-Sousa R. O Sistema de Avaliação e M onitoramento das Políticas e Programas Sociais: a experiência do Ministério do Desenvolvimento Social e Combate à Fome do Brasil. Brasília: UNESCO; 2006.

28. Rio de Janeiro. Tribunal de Contas do Rio de Janeiro. Auditoria Operacional - SM S - De 19 de abril a 14 de maio de 2007. [acessado 2010 maio 29]. Disponível em: http://www.tcm.rj.gov.br/WEB/Site/ N oticia D etalhe. aspx?noticia $=3497 \&$ detalhada $=0$

29. Cavalcanti LF, Zucco LP, Silva M M VA. A extensão universitária na prevenção da violência sexual. Revista Espaço para a Saúde 2005; 6(2):23-28

30. Minayo MC, Deslandes SF. Análise diagnóstica da Política Nacional de Saúde para a Redução de Acidentes e Violências. Rio de Janeiro: Fiocruz; 2007.

31. Deslandes SF, Assis SG, Gomes R, Njaine K, Constantino P. Famílias: parceiras ou usuárias eventuais? Análise de serviços de atenção a famílias com dinâmica de violência doméstica contra crianças e adolescentes. Brasília: UNICEF; 2004.

32. Gonçalves HS, Ferreira AL. A notificação da violência intrafamiliar contra crianças e adolescentes por profissionais de saúde. Cad Saude Publica 2002; 18(1):315-319.

Artigo apresentado em 27/10/2010

Aprovado em 31/03/2011

Versão final apresentada em 10/04/2011 